\title{
RESTAURACIÓN PSICOLÓGICA DE LOS FACTORES DETONANTES DE ESTRÉS EN LA MOVILIDAD URBANA. Caso de estudio: Sistema de Transporte Colectivo Metro
}

\author{
Juan Edmundo Echavarría Rodríguez \\ Universidad Nacional Autónoma de México \\ Director de Tesis: Mtro. Héctor Segura Carsi \\ yanused@hotmail.com
}

\section{RESUMEN}

La presente investigación afirma que las experiencias cotidianas al transitar y desplazarse en el Sistema de Transporte Colectivo Metro confluyen con diversos factores que detonan e incrementan el estrés en la población usuaria, convirtiéndose el estrés en un factor de morbilidad agregado a las condiciones de vulnerabilidad en salud que padecen los individuos; por lo que la intervención espacial desde la consideración de ambientes restauradores en estaciones del Metro incidirían en la mitigación de ese padecimiento.

Palabras Clave: Movilidad, Salud Mental, Estrés, Ambientes Restauradores.

\begin{abstract}
The present investigation affirms that the daily experiences when pass through and displace in the System of Collective Transport Metro they converge with diverse factors that detonate and increase the stress on the user population, becoming the stress in a factor of morbidity added to the conditions of vulnerability in health that suffer the individuals; so that the spatial intervention from the consideration of restauratives environments in stations of the Metro would have an impact on the mitigación of that condition.
\end{abstract}

Key Words: Mobility, Mental Health, Stress, Restorative Environments. 


\section{INTRODUCCIÓN}

Este trabajo plantea la posibilidad de mitigar el estrés cotidiano resultado de condiciones de movilidad urbana que requieren de esfuerzo físico y desgaste emocional reiterado aunados a la vulnerabilidad preexistente en lo que concierne a la salud de los individuos. Se apuesta por mitigar el estrés a través de la configuración espacial y el aprovechamiento de las instalaciones en estaciones del Sistema de Transporte Colectivo Metro (STC Metro) mezclando el recorrido por corredores y vestíbulos con una experiencia ambiental confortable, convirtiendo dichos espacios en lugares promotores de bienestar y de significativa importancia ambiental para la población; es decir, se apuesta por la intervención espacial en estaciones de la red del Metro para que funcionen como ambientes restauradores a pesar de ir en contra de los modos de uso comercial preexistentes. Esto con la finalidad de abrir posibilidades de estudio, análisis y reflexión sobre la importancia de la articulación entre ambientes naturales con espacios urbano-arquitectónicos que sean contemplados en futuras políticas de movilidad y transporte tendientes a mejorar la interacción de la población con su entorno urbano en pro de la salud mental y la calidad de vida. La tesis se desarrolló sobre los siguientes puntos: a) analizar los factores que impulsan el surgimiento del transporte Metro como un enlace entre la fuerza de trabajo y las actividades productivas, b) determinar si existen condiciones de vulnerabilidad social ligadas a factores ambientales en el STC Metro que influyen para la generación y acumulación de estrés en los usuarios de este transporte, asimismo, c) identificar si existen casos que puedan servir de referencia al apostar por la configuración de los espacios en estaciones del STC Metro para funcionar como ambientes restauradores.

El presente trabajo inicia con una breve mención sobre el surgimiento del STC Metro en la Ciudad de México como forma ampliada de las relaciones sociales productivas, posteriormente se expone que el STC Metro a pesar de ser la columna vertebral del transporte urbano se encuentra rebasado por la demanda de usuarios manifestando conflictos técnicos, tecnológicos, operativos y administrativos los cuales conllevan una serie de condiciones de vulnerabilidad social que inciden directamente en la calidad de vida de la población usuaria, así también se establecen las interacciones entre usuarios al interior de las estaciones y aquellas experiencias cotidianas generadoras de estrés; para finalizar, se propone la importancia de plantear la generación de espacios públicos incluyentes y estratégicos para incidir en la salud desde este sistema de transporte a través de ambientes restauradores para mitigar el estrés, sin que estos lleguen a fungir un papel meramente estético sino de efectivo sentido social y ambiental.

Dado el propósito de esta investigación evidentemente la metodología de corte cualitativo respaldada en nociones del urbanismo ecológico y la psicología ambiental es la que mejor se adecuó para su desarrollo, principalmente por la argumentación persuasiva que prioriza la importancia de la salud mental en las relaciones sociales de producción y la calidad de vida respecto de las condiciones de movilidad así como del entorno urbano. Este trabajo está desarrollado con información diversa tanto bibliográfica como hemerográfica, así como de textos en formato digital obtenidos de páginas web oficiales, sin embargo, se pudo apreciar que existe una carencia de investigaciones documentadas de este tipo; así como proyectos concretos tomados como puntos de comparación y/o de los cuales respaldarse como casos de estudio a fin de complementar estas nociones. Así también se llevó a cabo trabajo de campo mediante la observación participativa como método de análisis y deducción haciendo uso de herramientas tales como fotografía y video. A lo largo de este trabajo se exponen una serie de conceptos, argumentaciones teóricas e ideas que tratan de armar en su conjunto aportaciones razonablemente congruentes.

\section{EL STC METRO EN LA NATURALEZA DEL DESARROLLO PRODUCTIVO Y SOCIAL DE LA CIUDAD DE MÉXICO}

La Ciudad de México al ser la capital del país es también sede de capital financiero y concentra gran parte de las actividades culturales, educativas, comerciales, financieras y de servicios; de igual forma es el centro del poder administrativo y político a nivel nacional desde la época colonial. La concentración de actividades económicas diversas dieron como resultado el crecimiento urbano al cual se añadió el auge industrial a la par de la proliferación del automóvil y el incremento desproporcionado del tránsito urbano aumentando la importancia del transporte público en la vida de la Ciudad de México. El auge industrial a la par de la proliferación del automovil y el incremento desproporcionado del tránsito urbano, provocaban ya a mediados de siglo XX una creciente congestión, poniendo en cuestión los servicios de transporte incapaces de desahogar con fluidez la demanda 
excesiva, así también la falta de conectividad y los tiempos de traslado dieron pie a la posterior incorporación de un nuevo medio de transporte el cual sigue vigente hasta nuestros días, el Sistema de Transporte Colectivo Metro.

EI STC Metro se concibió para constituirse en la columna vertebral del transporte de la Ciudad de México, partiendo de un principio de centralidad conectando diferentes zonas y sus distintos tipos de actividades, por lo que en 1967 la construcción del STC Metro se llevó a cabo por la empresa mexicana de ingenieros civiles asociados (ICA) en medio del auge económico del país conocido como el periodo estabilizador, planeado, construido y enfocado principalmente para ser un medio de transporte rápido y eficaz al facilitar la movilidad de todos los ciudadanos, especialmente la clase obrera y aquellos sectores de menores ingresos quienes fungían como agentes primordiales en la edificación del México moderno así como en la generación de servicios; el STC Metro fue concebido como un medio de transporte que sirve principalmente al enlace de la fuerza de trabajo con las actividades productivas. En décadas posteriores la necesidad de prescindir de este transporte público así como la re-estructuración urbana que cubriese los principales puntos de la ciudad ligadas a zonas de nueva organización no se hizo esperar, permitiendo la descentralización comercial, habitacional y administrativa, por lo que se construyeron nuevas líneas conformando una Red que alcanza un total de 226, 488 km actualmente. ${ }^{1}$

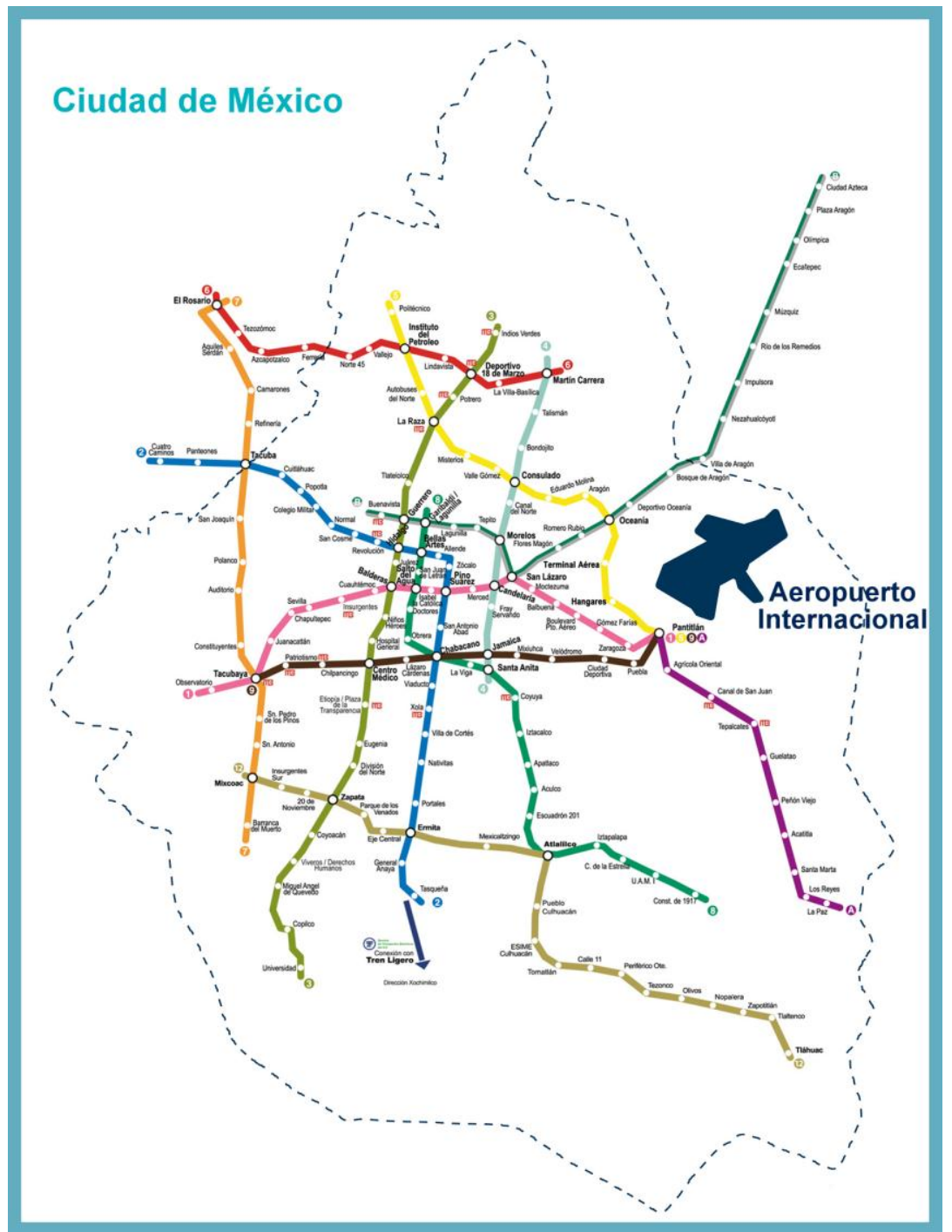

Título: Red del Metro.

Imagen propiedad de: Sistema de Transporte Colectivo Metro, con edición del autor. Abril 14 de 2017.

1 Sistema de Transporte Colectivo Metro. (2016). Recuperado de http://www.metro.df.gob.mx 
EI STC Metro a pesar de ser la columna vertebral del transporte urbano en la Ciudad de México, su crecimiento se ha dado de manera pausada a lo largo de casi 50 años, principalmente ante la falta de acuerdos y coordinación entre gobiernos de la ciudad y estatales para desarrollar una red metropolitana de transporte. Dichos gobiernos han desatendido la opción del Metro inclinándose por obras viales por lo que no alcanza a cubrir todas sus delegaciones y mucho menos la zona metropolitana dejando áreas sin atender y huecos que llenar a través de otros sistemas de transporte tales como Metrobus, Trolebus y RTP (Red de Transporte de Pasajeros); a pesar de ser un sistema de transporte económico, relativamente eficiente y rápido, además de encontrarse rebasado por la demanda creciente de usuarios (5.5 millones diariamente) manifestando conflictos técnicos, tecnológicos, operativos y administrativos.

\subsection{El uso de espacios en las estaciones del STC Metro y los Centros de Transferencia Modal (CETRAM) como estrategias comerciales}

Una de las características de la extensa red de estaciones del STC Metro es que se han convertido en espacios de uso diverso dados los distintos eventos artísticos, culturales, talleres didácticos, exposiciones fotográficas, plásticas, murales, presentaciones musicales, difusión de programas sociales, etcétera, que pueden encontrarse, por lo que los CETRAM (estaciones terminales más grandes en comparación con otras de la red) están siendo aprovechadas principalmente para uso comercial a través de actividades que no tienen cabida en el esquema original o la naturaleza objetiva para los cuales fueron creados. Los CETRAM fueron concebidos como lugares en los cuales confluirían no sólo distintos modos de transporte sino como reguladores del crecimiento urbano, sin embargo, hoy en día manifiestan diversos problemas derivados de la intermodalidad necesaria para atender los viajes diarios tales como difícil accesibilidad peatonal tanto por la invasión del espacio público como por la saturación de accesos vehiculares, riesgos viales, obstrucciones en el flujo del transporte público concesionado, inseguridad, contaminación ambiental, deterioro de infraestructura y por consiguiente el deterioro del entorno urbano circundante.

El Programa General de desarrollo del Distrito Federal a través del Programa Integral de Movilidad 2013 - 2018 conciben a los CETRAM como áreas de oportunidad cuyo eje estratégico es impulsar el reordenamiento de los mismos en función de su adecuada localización, infraestructura y servicios, con la finalidad de propiciar condiciones óptimas de seguridad, operación y orden, así como una intermodalidad eficiente. Es decir, los CETRAM se visualizan como escenarios futuros de desarrollo para la Ciudad teniendo como premisa la multifuncionalidad de la infraestructura del transporte, poniendo a los usuarios y habitantes de las áreas de influencia en el centro de estas mejoras pretendiendo elevar y mejorar su calidad de vida incorporando componentes comerciales, habitacionales y de usos mixtos. Sin embargo, la prioridad de estos proyectos radica en el monopolio de la operación multimodal del transporte público y la explotación comercial al ser la iniciativa privada la que cubra gran parte o la totalidad de la inversión en infraestructura, por lo que el verdadero beneficio en movilidad y lo que respecta a la conexión intermodal queda en duda. Esta tendencia de explotación comercial se extiende a otras estaciones terminales lo cual genera una mayor fragmentación del entorno urbano, una mayor desigualdad social e incluso trastoca la salud de los habitantes al enfocarse a fines de mercado como objetivo principal y no atender las necesidades sociales.
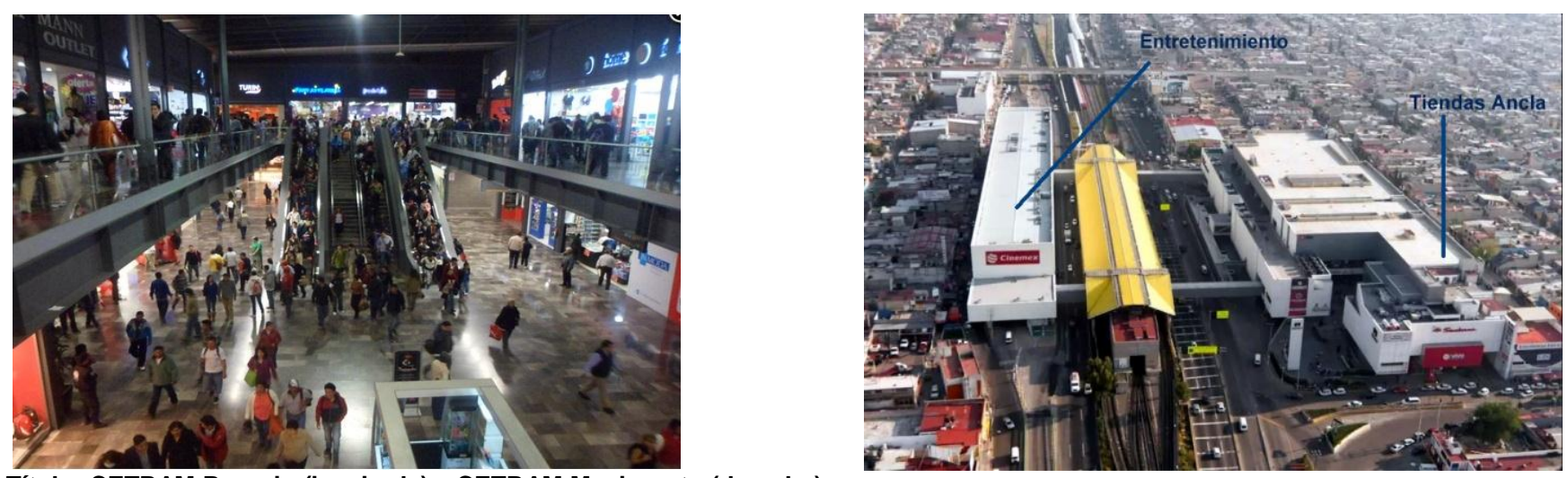

Título: CETRAM Rosario (izquierda) y CETRAM Mexipuerto (derecha). 


\section{EL ESTRÉS GENERADO EN LA MOVILIDAD URBANA Y EL USO DEL TRANSPORTE METRO, UN FACTOR AGREGADO A LA VULNERABILIDAD SOCIAL}

Sin importar cualesquiera que sean las condiciones objetivas de desplazamiento de los individuos, la movilidad urbana es una necesidad básica que debe ser satisfecha donde el esfuerzo que requieren los desplazamientos para cubrir dichas actividades no repercuta negativamente en la salud, la movilidad urbana se vincula con la salud física y mental en correspondencia con el desarrollo humano y calidad de vida, pues la movilidad en esencia supone la realización de actividades diversas y el disfrute de la ciudad a través de desplazamientos más seguros, menos prolongados y desgastantes; sin embargo, en la Ciudad de México los desplazamientos tienen un costo de carácter social que afecta el bienestar de sus habitantes al destinar mayor tiempo de traslado, esfuerzo físico y mental para afrontar la deficiente movilidad así como la calidad de los entornos donde se desplace.

El estrés está directamente relacionado con la cantidad e intensidad de estímulos con los cuales vivimos en la ciudad, tales como el ruido, tránsito automovilístico, la cantidad de basura en las calles, construcciones y comercios ambulantes que obstruyen el libre andar de peatones, etcétera; en suma, una serie de condiciones y experiencias negativas que parecieran carecer de importancia pero ante las cuales los individuos necesariamente tendrán que adaptarse en la medida de sus posibilidades sin importar condición física, género o estatus social. Cabe señalar que el estrés no es necesariamente malo, hemos aprendido a vivir con él canalizándolo de acuerdo a las exigencias diarias de la modernidad y al desplazarnos por la ciudad, pero quienes están más expuestos a padecerlo y desencadenar estrés crónico son los sectores de la población más vulnerables pues se desenvuelven en condiciones y ambientes poco favorables. Cabe destacar que las personas que viven en pobreza o se encuentran en condiciones de vulnerabilidad tienden a presentar más problemas de salud que el resto de la población, así también se puede relacionar que diversos problemas de salud física y mental de este sector de la población están relacionados con las condiciones estresantes de trabajo aunadas a las de desplazamiento; por lo que es necesario la creación y ejecución de medidas regulatorias para el diseño y construcción de espacios, entornos e infraestructura del transporte público que más allá de ser más funcionales, disminuya y evite la exposición a ambientes insalubres, situaciones y condiciones nocivas para la clase trabajadora, pues a la par del crecimiento urbano de la ciudad van apareciendo nuevos panoramas epidemiológicos.

Por ejemplo, las personas invierten mucho tiempo en trasladarse de sus hogares al lugar de trabajo y viceversa, lo cual ya representa en sí mismo un desgate para todo individuo; sin embargo se pierde de vista que el tiempo de desplazamiento es tan problemático como la experiencia del viaje en sí misma y esta a su vez, pone de manifiesto que las dificultades que puedan suscitarse en los trayectos de los individuos dependerá en gran medida del desempeño que estos tengan en cualquier lugar sin importar las condiciones espaciales y ambientales bajo las cuales se desplace; así también, las experiencias de los recorridos dependerá de la interpretación que el individuo haga del mismo y de sus habilidades de afrontamiento. Desde hace tiempo se ha delegado a la población el fomento de valores y actitudes responsables respecto a su salud, por ejemplo, los individuos cargan con la responsabilidad de contar con salud y bienestar óptimos sin importar las condiciones, situaciones y posibles vulnerabilidades a los cuales estén expuestos durante sus desplazamientos por la ciudad y espacios en los cuales se desenvuelva cotidianamente, por ejemplo los centros de trabajo. La identificación de condiciones de trabajo nocivas, potencialmente estresantes y asociadas con daños a la salud mental quedan de lado, pues los accidentes de trabajo se atribuyen principalmente al factor humano, así también las condiciones ambientales de trabajo que podrían incidir en aquellos aspectos psicológicos tampoco son tomadas en cuenta como riesgos para la salud. Las medidas de seguridad e higiene y protección civil se enfocan meramente en la salud física de los individuos en donde la salud mental deriva en la prevención y atención de la misma desde un esquema tradicionalista y reduccionista al contemplar exclusivamente el contexto de las relaciones sociales en las cuales se ven inmersos perdiendo de vista la influencia ambiental y de los entornos urbanos.

La flexibilización de las relaciones laborales y la precarización del empleo limitan cada vez más los derechos del trabajador como la seguridad social, derechos a la salud y la ausencia de protección contra riesgos de trabajo por lo que más allá de las condiciones espaciales de trabajo y contractuales laborales deficientes, las clases bajas se encuentran inmersas en entornos e infraestructura de trasporte público deficiente ligadas a situaciones 
de estrés; sin embargo, el estrés no es considerado como un padecimiento o enfermedad relacionada con el desempeño y esfuerzo requerido previo y durante la realización de cualquier trabajo, por lo que en nuestro país no está contemplado como factor de riesgo en la Ley Federal del Trabajo. ${ }^{2}$ Dicha Ley contempla un Reglamento Federal de Seguridad y Salud en el Trabajo (publicado el 13 de Noviembre de 2016 en el Diario Oficial de la Federación); cuyo reglamento tiene por objeto establecer las disposiciones en materia de Seguridad y Salud en el Trabajo, a efecto de contar con las condiciones que permitan prevenir riesgos y de esta manera garantizar a los trabajadores el derecho a desempeñar sus actividades en entornos que aseguren su vida y salud. A continuación se enuncian dichas disposiciones:

\section{Título Noveno - Riesgos de Trabajo}

Artículo 473.- Riesgos de trabajos son los accidentes y enfermedades a que están expuestos los trabajadores en ejercicio o con motivo del trabajo.

Artículo 474.- Accidente de trabajo es toda lesión orgánica o perturbación funcional, inmediata o posterior, o la muerte, producida repentinamente en ejercicio, o con motivo del trabajo, cualesquiera que sean el lugar y el tiempo en que se preste. Quedan incluidos en la definición anterior los accidentes que se produzcan al trasladarse el trabajador directamente de su domicilio al lugar del trabajo y de éste a aquel.

En cualquier centro laboral los empleados están expuestos a riesgos de trabajo, por lo que es necesario llevar a cabo acciones encaminadas a reducir dichos riesgos, garantizar la seguridad y mejorar la salud de los trabajadores; por lo que en estricto sentido y en apego al Reglamento Federal de Seguridad y Salud en el Trabajo si bien el Transporte Metro no es un centro laboral, puede considerarse como una extensión del mismo al ser el entorno en el cual los individuos transcurren una gran parte del tiempo de traslado, entorno en el cual realizan desgaste físico y cognitivo para cumplir con las encomiendas del sector productivo. La salud mental al no circunscribirse a las enfermedades incapacitantes, a pesar de existir un respaldo legal que contempla que todo trabajador asalariado tiene cubierto cualquier riesgo a su salud en los trayectos que este realice para cumplir con sus funciones laborales, ante la carencia de mecanismos regulatorios, de vigilancia, y ejecutorios de sanción, la propia legislación deja desprotegidos a la clase obrera. Dado que el STC Metro es un transporte destinado para la movilidad de la fuerza laboral y está delimitado a la naturaleza del desarrollo productivo, a pesar de que la clase obrera y trabajadora es capaz de soportar todo lo que se suscite en él, es importante preservar la salud de las colectividades industriales.

\subsection{Fuentes de estrés ambiental en el STC Metro}

La extensión territorial de la Ciudad de México y su compleja actividad social y económica dan como resultado una amplia demanda de movilidad, pues conlleva la necesidad de trasladarse de un lugar a otro a través de distancias cada vez mayores y por tanto destinar más tiempo y gasto de recursos para desplazarse ya sea del hogar al trabajo, al colegio, hacía lugares de ocio y recreación, etcétera; dichas complicaciones en la movilidad urbana propician un desgaste continuo en el bienestar físico y la inestabilidad en estados de ánimo así como cambios en el comportamiento habitual, siendo el estrés el común denominador de un malestar generalizado sin que la población se percate del impacto que este tiene al experimentarlo por tiempos prolongados. El STC Metro a pesar de contar con estaciones de relativa facilidad de acceso no considera la diversidad de necesidades específicas pues las mujeres, niños y niñas, personas con discapacidad y adultos mayores son quienes resultan más afectados que el resto de la población usuaria ya que el sistema muy poco ha intervenido o gestionado por hacer evidentes las experiencias y necesidades de movilidad diferenciadas de la población de mujeres y hombres en materia de movilidad pues dificulta y obstaculiza el flujo de personas en las estaciones ante una logística de desahogo de usuarios ineficiente. La población usuaria del transporte Metro requiere de exigencia física y mental por mucho distintas a los sectores de clase media y alta en sus trayectos y desplazamientos cotidianos por la ciudad, si a ello consideramos las exigencias a las que se someten las personas con algún tipo de discapacidad las manifestaciones de estrés, trastornos en la conducta y cognición se ven agravadas.

Según el Gabinete de Comunicación Estratégica (2016:07), el Indice de Calidad de Vida (INCAV) comprende

2 "En México, durante el año de 1904; se introduce la idea de riesgo profesional en la Ley del Trabajo del Estado de México, posteriormente en el año de 1912, se expide el Reglamento de Policía Minera y Seguridad en el Trabajo de las minas. Estos dos reglamentos sirvieron como base para que se legislara en la Constitución de 1917 la prevención de riesgos de trabajo, quedando concretada en el mandato constitucional 123 , sentando los precedentes históricos a nivel mundial desde la segunda década del presente siglo. Reconociendo el Estado el Derecho que tienen los mexicanos de garantizar una existencia digna para ellos." (Jasso de Jesús, 1998:10). 
dentro de sus variables, la movilidad en la ciudad y el medio ambiente como indicadores que determinan condiciones optimas en los cuales se desenvuelve la población, aunque en estricto sentido bajo un análisis riguroso si se aplican estos parámetros de medición a calificar los entornos en los cuales se desplazan y desenvuelven los usuarios del transporte Metro, se pondría en duda la calificación otorgada a la Ciudad de México en cuanto a calidad de vida. EI STC Metro a pesar de ser la columna vertebral del transporte urbano en la Ciudad de México se encuentra rebasado por la demanda de usuarios, con la activación de contingencias ambientales y la ampliación del programa "hoy no circula" como medidas emergentes de restricción vehicular para reducir la contaminación atmosférica en la zona metropolitana de la ciudad de México, en el periodo de Abril a Junio de 2016 llevó a un incremento en el número de usuarios de entre 7 y $15 \%$ por día en el STC Metro. ${ }^{3}$ Para el presente año (2017), se espera un aumento en el número de usuarios (137 mil 500 diarios aproximadamente) ante el alza en los precios de la gasolina y el constante aumento inflacionario, lo cual provoca que muchas personas prefieran este transporte público pues sigue siendo la mejor alternativa para movilizarse en la Ciudad además de tener un impacto menos significativo en el gasto diario. ${ }^{4}$ Dichos incrementos en la población requerirá de mejoras en este sistema de transporte para garantizar un funcionamiento optimo, aunque la calidad de servicio puede seguir siendo cuestionada por las condiciones de movilidad anteriormente expuestas. En el siguiente esquema se plantea el contexto bajo el cual se desenvuelve la población usuaria y aquellas causas estructurales que repercuten tanto en la capacidad operativa de la red como en la salud de millones de personas que utilizan este transporte diariamente.

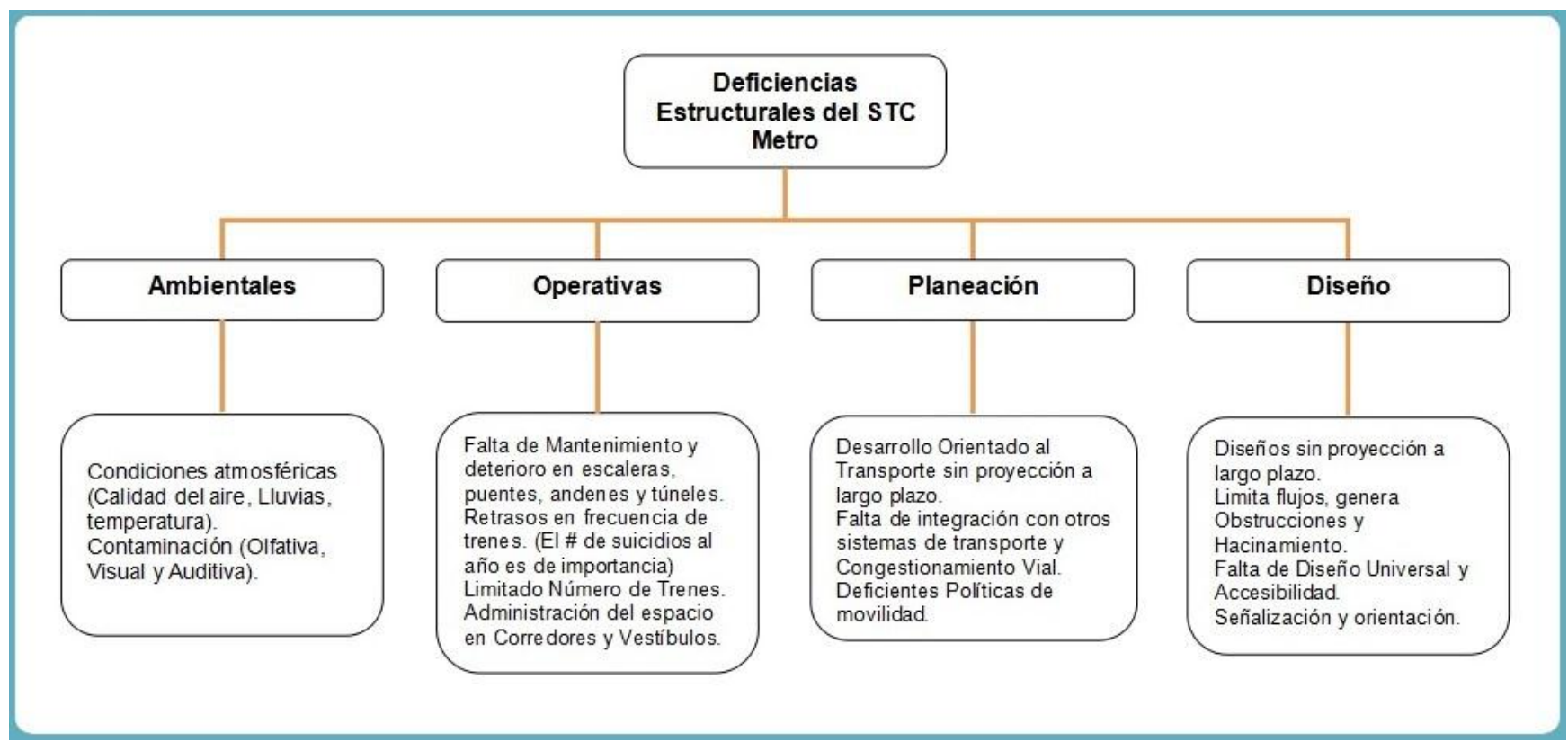

Título: Deficiencias Estructurales del STC Metro.

Elaboración Propia

Más allá de las deficiencias en el servicio, existen problemas de índole económico, social y cultural pues a pesar de existir la Ley de Movilidad de la Ciudad de México la cual prevé el diseño e implementación de políticas, programas y acciones públicas en materia de movilidad, la CDHDF (2016:16) reitera que esta Ley deberá procurar que los componentes del sistema de movilidad cuenten con los requerimientos y las propiedades aceptables para cumplir con su función, producir el menor daño ambiental, ofrecer un espacio apropiado y confortable para las personas y encontrarse en buen estado, en condiciones higiénicas, de seguridad, y con mantenimiento regular, para proporcionar una adecuada experiencia de viaje; es evidente que la población está expuesta a estímulos ambientales diversos así como a una sobrecarga de información por distintas fuentes como lo son la contaminación visual, auditiva y olfativa, principalmente en los CETRAM. Así también en estaciones que

\footnotetext{
3 Zavala, L. (13 de Abril de 2016). Aumentó 15\% afluencia de usuarios del Metro por Hoy no Circula. Diario DF. Recuperado de www.diariodf.mx

${ }^{4}$ López, J. (09 de Enero de 2017). Más personas ocuparán el Metro por el alza a las gasolinas. Periódico Excelsior. Recuperado de http://www.excelsior.com.mx
} 
pueden apreciarse bien iluminadas, monitoreadas y vigiladas, se presentan actos de robo, acoso sexual y agresiones físicas por mencionar algunos, por lo que dichas asociaciones pueden ser causantes de estrés al transitar por estaciones estigmatizadas.

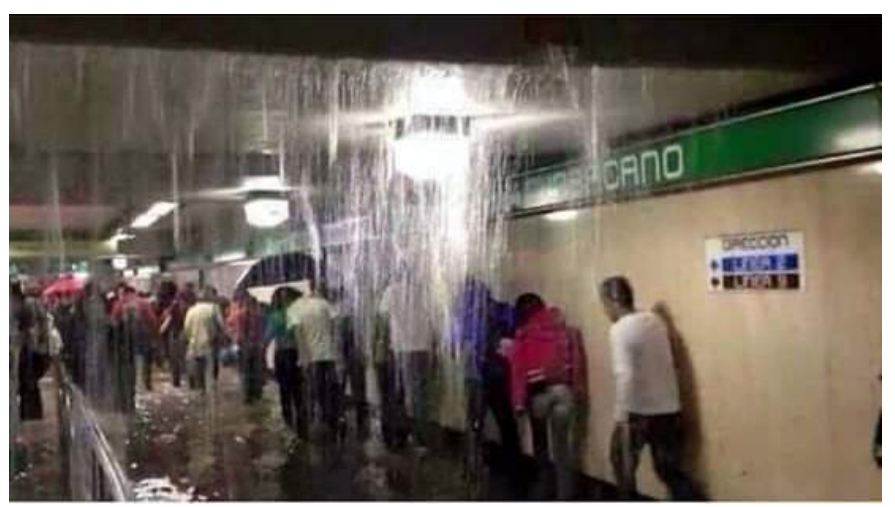

Título: Riesgos por inundación en estación subterránea.

Imagen propiedad de: Imagen Radio. Agosto de 2016.

Otros factores que contribuye a la manifestación del estrés y de otros malestares durante los recorridos de la población usuaria es el incremento de la temperatura ocasionada por el cúmulo de personas y el esfuerzo físico de estas mismas dentro de los andenes y vagones al caminar y avanzar, la gran cantidad de luz artificial para mantener iluminados los trenes, los corredores y comercios establecidos al interior de las estaciones; así como por la ausencia del flujo de aire acondicionado y el proveniente del exterior. Así también, aquellas estaciones subterráneas de mayor afluencia de personas son auténticas islas de calor dada la cantidad de locales comerciales que contribuyen a incrementar la temperatura hasta 39 o 40 grados centígrados de acuerdo con el estudio de Espacios y Locales Comerciales en 50 de las Estaciones Críticas Seleccionadas que conforman la Red del STC. ${ }^{5}$ Es importante considerar que los usuarios del metro se encuentran constantemente expuestos a iluminación tanto artificial como natural; en los horarios en los cuales la luz natural ha descendido y es hora de regresar a casa, se exponen a la iluminación artificial al interior de las estaciones lo cual podría generar alteraciones en el ciclo de sueño a causa de la sobre-estimulación de luz artificial, incrementándose los periodos de vigilia lo que conlleva a alteraciones cognitivas, cansancio y el riesgo de otros padecimientos. La calidad del aire es cuestionable ante la falta de filtros para regular el aire contaminado que proviene de la superficie hacia el interior de las estaciones, en muchas estaciones se encuentran rejillas a nivel de calle por las cuales ingresa tanto el polvo y el humo de los vehículos como la filtración de agua de lluvia. Diversas estaciones subterráneas sufren de estas filtraciones de agua llegando a inundar los corredores limitando el flujo de usuarios exponiéndolos a padecer algún accidente. La basura es un problema grave por su exposición al aire libre y los posibles focos de infección por los comercios de alimentos pues la basura está presente en casi todas las estaciones principalmente al exterior siendo la misma población usuaria la que más basura genera. Hasta este punto, se exponen las condiciones espaciales y ambientales bajo el cual se desenvuelve la población usuaria del STC Metro y que derivan en estrés.

\subsection{Experiencias cotidianas al interior del STC Metro generadoras de estrés}

El Metro también manifiesta una gran diversidad de historias tales como confrontaciones entre individuos, ya sea por la disputa de lugares y asientos al ingresar a los vagones, por el hecho de venir demasiado apretados 0 incluso por el simple hecho de voltearse a ver, así como enfrentamientos entre policías y vendedores ambulantes al querer desalojarlos; acosos y abusos sexuales hacia hombres y mujeres de diferentes edades. Historias en la que también son participes miles de usuarios, músicos, mimos, vagabundos, tribus urbanas, etcétera, por lo que transitar por las estaciones y vagones del metro es toda una experiencia sensorial. Ante una elevada densidad de usuarios en las estaciones y vagones de tren, el hacinamiento es el factor principal para detonar el estrés e inducir la percepción de otros agentes estresores que pueden aunarse. La saturación y congestión de vagones por una gran cantidad de personas que comparten de manera obligada estos espacios aunque sea

\footnotetext{
5 Pazos, F. (28 de Enero de 2015). Urgen retirar locales del interior del Metro. Periódico Excelsior. Recuperado de http://www.excelsior.com.mx
} 
temporalmente, conlleva conductas de defensa del espacio personal pues uno de los efectos del estrés consiste en incrementar el estado de alerta y preparar al individuo para responder ante una amenaza o peligro. Por ejemplo, las mujeres experimentan estrés y estados de mayor alerta ante el cuidado de sí mismas, niñas, niños, adultos mayores la protección de pertenencias al ingresar al anden o al vagón de los trenes, y la búsqueda de espacios libres de acoso. Con toda esa carga de información, si una persona no cuenta con un adecuado manejo del estrés puede manifestar conductas agresivas como una dificultad para adaptarse a la situación, sin embargo, la población que recurre a este sistema de transporte de manera reiterada permanece en un contexto de situaciones estresantes lo que abre la posibilidad de afrontar dichas condiciones y situaciones mediante la confrontación.

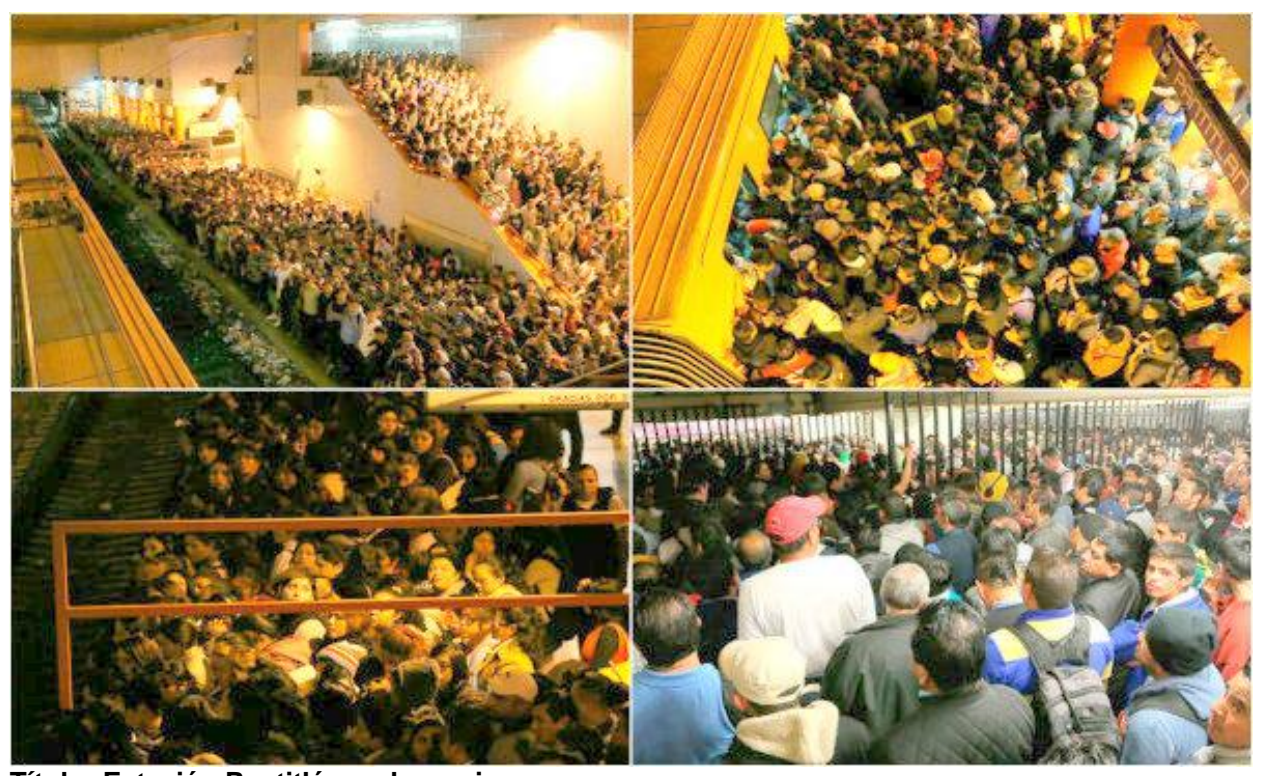

Título: Estación Pantitlán en hora pico.

Imagen propiedad de 24 horas, el diario sin límites. Febrero 11, 2016.

Si bien es complejo y difícil modificar el flujo de usuarios en este sistema de transporte, así como las disposiciones espaciales para un mejor confort, la intervención espacial recaería en los mecanismos bajo los cuales se podría disminuir la agresividad entre los usuarios como respuesta a los estados de alerta y tensión, respuestas que a su vez están permeadas por condiciones de género. Por ejemplo, en corredores y vagones tanto hombres como mujeres pueden encontrarse ante cierta vulnerabilidad de padecer situaciones de violencia, por un lado, las mujeres se encuentran expuestas a ser víctimas de abuso y violencia sexual y los hombres, expuestos a experimentar violencia física como parte de comportamientos agresivos "propios" del género masculino. Respecto a la interacción y contacto social puede afirmarse que al menos en este sistema de transporte público, se da un fenómeno de cosificación de las personas ante la masividad y el cúmulo de usuarios que comparten el mismo espacio, invisibilizando la empatía y solidaridad entre individuos. Tal y como mencionan Tomás Rafael y Amérigo María (2001), en el caso específico del transporte Metro la sobrecarga de información puede manifestarse al observar que los usuarios evitan la interacción social, el contacto visual y realizar expresiones gestuales ya que estas pueden ser interpretadas como poco gratas e incluso hostiles, por lo que en condiciones de hacinamiento, la distancia interpersonal y la privacidad son elementos indispensables para la interpretación subjetiva de la información y que permitirán que el individuo tenga la posibilidad de controlar el contacto e interacción con otras personas mediante la conducta; algo que en los andenes, vagones y trenes del STC Metro es muy difícil de regular.

La interpretación subjetiva de la información derivada del ambiente y el contacto social es fundamental para el desarrollo de estrategias que permitan afrontar las situaciones estresantes, la estrategia a la que cada individuo recurra dependerá de su capacidad de adaptación y tolerancia fisiológica, e inclusive de su educación cultural tal como se muestra en la siguiente tabla. 


\begin{tabular}{|c|c|c|c|}
\hline \multirow{2}{*}{$\begin{array}{l}\text { Conducta } \\
\text { socio-espacial }\end{array}$} & \multirow[b]{2}{*}{ Acción o respuesta del individuo } & \multicolumn{2}{|c|}{$\begin{array}{c}\text { Estrategias de afrontamiento del } \\
\text { estrés }\end{array}$} \\
\hline & & $\begin{array}{l}\text { Al interior del } \\
\text { Vagón }\end{array}$ & $\begin{array}{c}\text { En corredores y } \\
\text { vestibulos de las } \\
\text { Estaciones }\end{array}$ \\
\hline $\begin{array}{l}\text { Patrones de } \\
\text { ocupación del } \\
\text { espacio. }\end{array}$ & $\begin{array}{l}\text { Zonas destinadas a hombres y mujeres, descanso y } \\
\text { espera en áreas con posibilidad de respaldo, dirigirse } \\
\text { al final del andén o zona de menor aglomeración. }\end{array}$ & \multirow{3}{*}{$\begin{array}{c}\text { Se evita la } \\
\text { interacción social, } \\
\text { el contacto visual, } \\
\text { se recurre al uso } \\
\text { de distractores } \\
\text { tales como leer, } \\
\text { maquillarse, tejer, } \\
\text { el uso de } \\
\text { celulares y } \\
\text { dispositivos de } \\
\text { audio y video. }\end{array}$} & \multirow{3}{*}{$\begin{array}{l}\text { Distraerse con } \\
\text { pequeñas } \\
\text { exposiciones } \\
\text { plásticas y } \\
\text { fotográficas, } \\
\text { murales, } \\
\text { presentaciones } \\
\text { artisticas, } \\
\text { musicales y/o en } \\
\text { talleres diversos. }\end{array}$} \\
\hline $\begin{array}{l}\text { Conductas } \\
\text { asociadas con el } \\
\text { acceso y descenso } \\
\text { del tren. }\end{array}$ & Empujar y/o preguntary pedir espacio para avanzar. & & \\
\hline $\begin{array}{l}\text { Conductas y } \\
\text { actitudes } \\
\text { territoriales y de } \\
\text { defensa del espacio } \\
\text { personal en el } \\
\text { transcurso del viaje. }\end{array}$ & $\begin{array}{l}\text { Cambio de posición, cambio de vagón, cambio de } \\
\text { lugar dentro del vagón, ocupación de asientos, gestos } \\
\text { o expresiones corporales de defensa u hostilidad, } \\
\text { confrontación. La protección y el cuidado de } \\
\text { pertenencias asi como de niñas, niños, } \\
\text { discapacitados y adultos mayores. }\end{array}$ & & \\
\hline
\end{tabular}

Título: Conducta social y tipos de respuesta ante diferentes fuentes de estrés en el STC Metro Elaboración propia.

Cabe señalar que en cada individuo la intensidad de los efectos desfavorables al manifestar estados de tensión depende de los rasgos de personalidad, es decir, cabe la posibilidad de que algún trastorno mental preexista en el individuo, el cual, al aumentar los estados contantes de estrés, puede desencadenarse y/o incrementarse el trastorno preexistente. Ahora bien, si lo anterior lo añadimos a las dificultades de desplazamiento que padece una persona con discapacidad lo anterior se torna aún más grave, pues las personas con discapacidades motrices al representar una minoría de la población han sido excluidos en el diseño de los entornos urbanos y espacios públicos. Hasta ahora se ha considerado como eje transversal de la investigación, las condiciones deficientes del Transporte Metro y aquellas situaciones que vulneran a la fuerza de trabajo en sus desplazamientos cotidianos a través de este sistema, a continuación se plantea la importancia de incorporar ambientes restauradores en las estaciones del Metro para incidir en la mitigación del estrés, entrelazando referencias teóricas y empíricas que orienten al lector a vislumbrar la intervención espacial.

\section{LA NATURALEZA URBANA COMO FUENTE DE RESTAURACIÓN PSICOLÓGICA}

Diversos estudios de investigadores como Kaplan, S. (1995), Kaplan, R. y Kaplan S. (1989), Hernández B, Hidalgo C. (2005), Cooper, Marcus (2007), Van den Berg, A. y Hartig, T. Staats, H. (2007), Ulrich, R.S. y Simoons, R.F. (1991), han demostrado que el contacto con la naturaleza puede contribuir a reducir el estrés y a promover estados de humor positivos y un adecuado funcionamiento cognitivo. Estos estudios brindaron soporte a la influencia positiva de la naturaleza en las personas; de la percepción de aquellos escenarios que contribuyen al bienestar físico y mental de las personas se desprende el estudio de los ambientes restauradores y de la restauración psicológica. Al estar en contacto con la naturaleza de manera inconsciente se adquiere cierta restauración psicológica la cual es un proceso de recuperación cognitiva y emocional ante las demandas de la vida cotidiana, cabe señalar que existen diferencias en la percepción ambiental respecto a los entornos naturales y los entornos urbanos construidos influenciadas por condiciones de género, por ejemplo, las mujeres prefieren espacios limpios y seguros para ellas y/o sus hijas/os; aunque sin importar distinción de género, clase o raza, estos ambientes restauradores pueden ser vistos como promotores de bienestar individual y colectivo.

Así como existen entornos urbanos caóticos con excesivos estímulos estresantes, también hay espacios que pueden brindar beneficios en diversos aspectos a la salud mental principalmente aumentando las posibilidades de realizar alguna actividad física, reduciendo el estrés, y proveyendo de relajación, estos espacios se caracterizan por contar con áreas verdes las cuales son vitales para mejorar la salud de la población pues 
mitigan el ruido y la contaminación atmosférica, renuevan el aire, generan microclimas agradables y proporcionan refugio para la vida silvestre al tiempo que relajan y suponen una distracción necesaria. La gran mayoría de los habitantes tiende a preferir los ambientes naturales pues la información ambiental es menos estresante. ¿Pero cómo se puede explicar la necesidad del ser humano de establecer contacto con la naturaleza de manera consciente o inconsciente? Edward $\mathrm{O}$. Wilson, entomológo y biólogo estadounidense de la universidad de Harvard, plantea la tesis que el contacto con la naturaleza es esencial para el desarrollo psicológico, introduciendo el concepto de Biofilia. "La biofilia se entiende como la conexión innata que los seres humanos poseen hacia todos los seres vivos y entornos naturales. Está conexión involucra aspectos emocionales, morales y cognitivos. Argumenta que como nuestra especie evolucionó en espacios naturales, todas estas habilidades psicológicas le proporcionaron información del entorno que le permitían sobrevivir. Algo a tener en cuenta es que aún y cuando en la actualidad los seres humanos no están tanto en contacto con la naturaleza, estas habilidades siguen presentes". (Sánchez, 2015:394).

Un serio problema ambiental al que se enfrentan los habitantes en la ciudad es la falta de naturaleza urbana, los parques, jardines, camellones y pequeñas arboledas son auténticos oasis en medio de la urbe, valiosos recursos para mejorar la salud y el bienestar de las personas, pero desafortunadamente se encuentran invadidos y opacados por el conjunto de estructuras de metal y concreto, hoy en día todo elemento natural dentro de lo construido ha pasado a ser objeto meramente estético, convirtiéndose así en un objeto añadido al escenario urbano. En la Ciudad de México por lo general las áreas verdes, parques y jardines aparecen alterados o deteriorados, pues el crecimiento de la ciudad prioriza las actividades de producción por encima de las actividades de esparcimiento por lo que desafortunadamente la distribución de ambientes naturales no se da de manera equilibrada en comparación con los entornos urbanos.

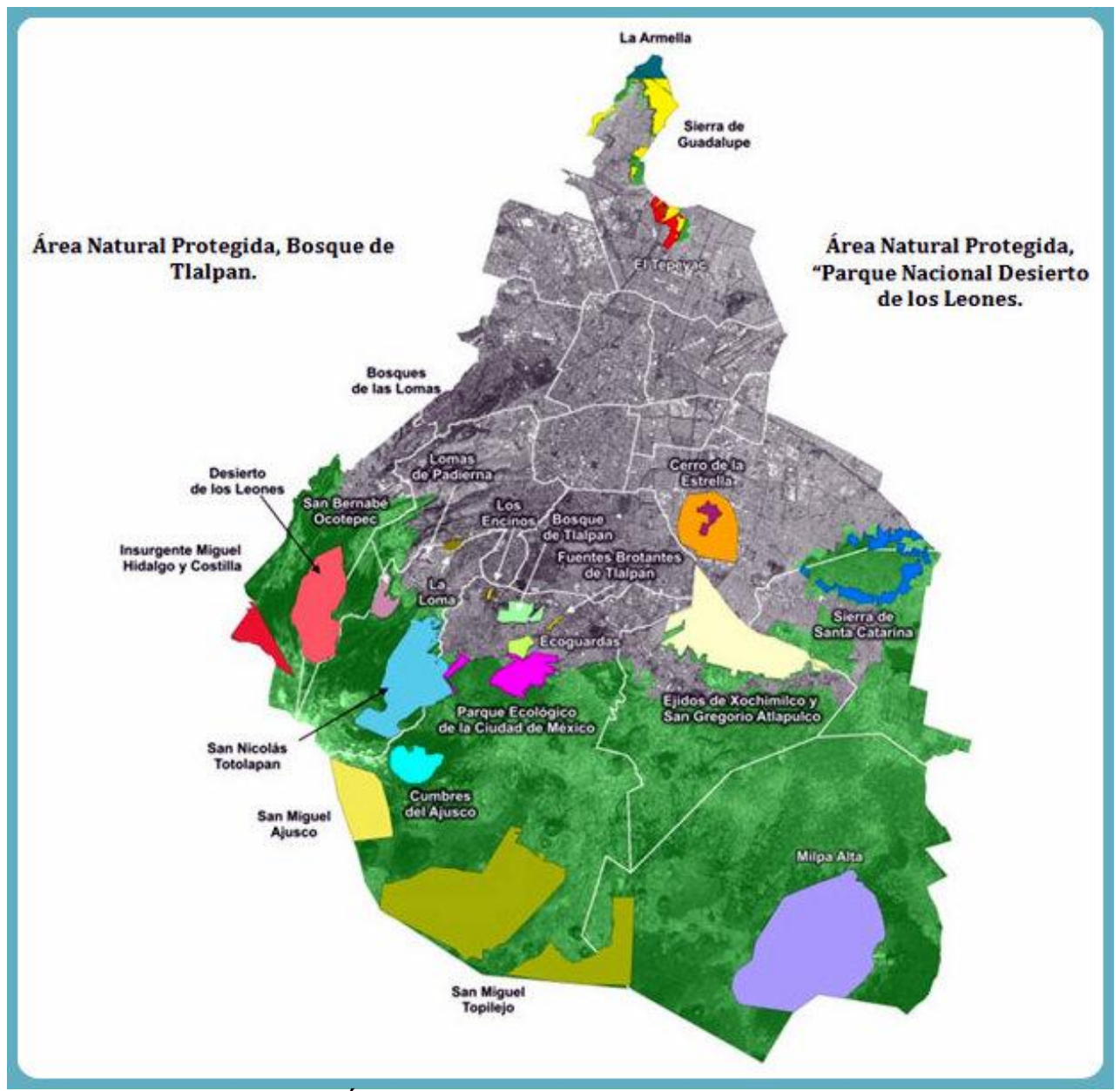

Título: Inventario General de Áreas Verdes del Distrito Federal.

Imagen propiedad de: Secretaría de Medio Ambiente. Marzo 10, 2017. 
Nuestra relación con la naturaleza se ve empobrecida al estar inmersa en la urbe por lo que carece de valor ambiental pasando a ser meros elementos estéticos que embellecen a la ciudad. Aquellas colonias con un alto contenido de parques, jardines y áreas verdes, presentan una gran afluencia por parte de personas que viven en sus zonas circundantes, convirtiendo dichos lugares en espacios públicos a través de prácticas de apropiación del espacio. Barrios de alta densidad que permiten a las personas gozar de cierta seguridad y diversidad de usos, servicios, actividades recreativas y de esparcimiento favoreciendo en cierta medida la interacción social; contradictoriamente también se convierten en zonas atractivas para la inversión mediante la explotación del uso de suelo.

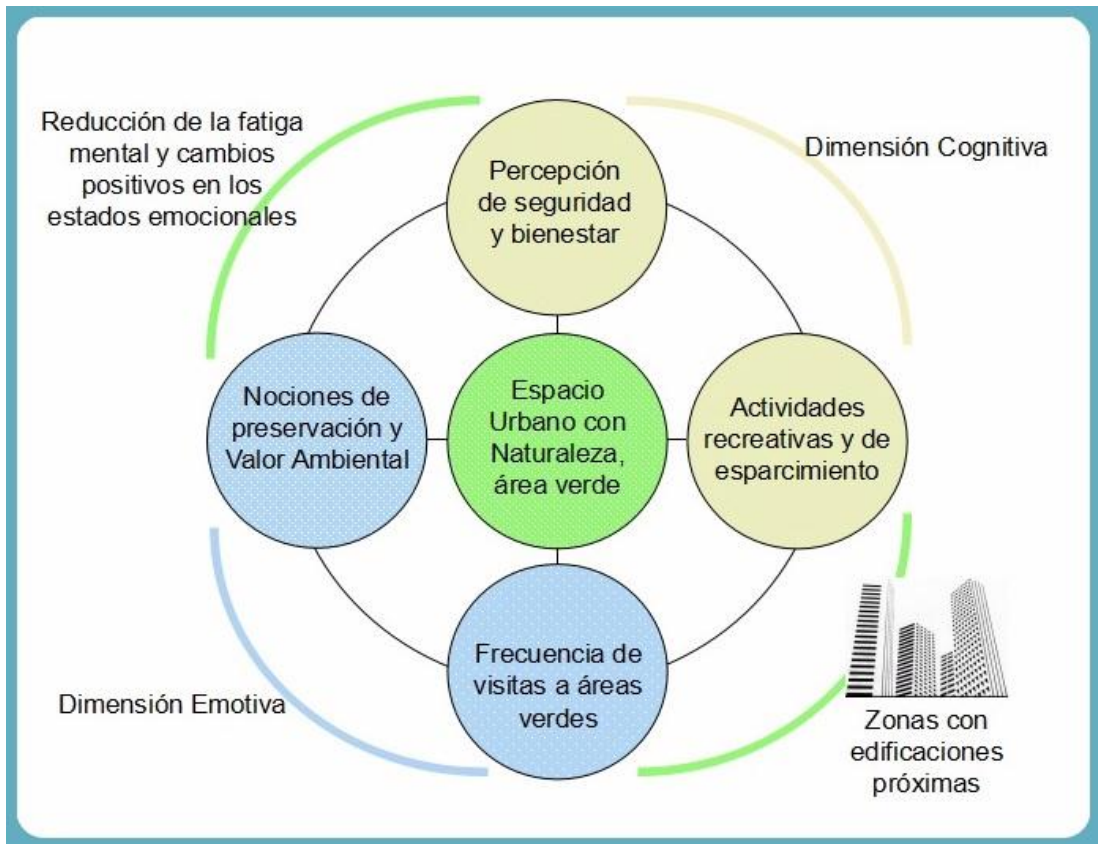

Título: Conformación de la preferencia ambiental en áreas con naturaleza urbana Elaboración Propia

\begin{tabular}{|c|c|c|}
\hline Recurso Ambiental & $\begin{array}{c}\text { Efectos Favorables } \\
\text { (Potencial del ambiente restaurador) }\end{array}$ & Efectos Desfavorables \\
\hline $\begin{array}{l}\text { Bosques, parques, } \\
\text { jardines, escenarios } \\
\text { construidos con la } \\
\text { incorporación de } \\
\text { elementos } \\
\text { naturales. }\end{array}$ & $\begin{array}{l}\text { Reducción de la fatiga mental. } \\
\text { Adquirir la habilidad de relajarse más rápido y la } \\
\text { reducción del estrés. } \\
\text { Cambios positivos en los estados emocionales. } \\
\text { Incide y promueve la cohesión social. }\end{array}$ & $\begin{array}{l}\text { Manifestación de alergias por el contacto con flora y } \\
\text { fauna. } \\
\text { Percepción de inseguridad ante la ausencia de } \\
\text { iluminación y la abundancia de vegetación la cual } \\
\text { impide la visibilidad en diversas zonas. }\end{array}$ \\
\hline $\begin{array}{l}\text { Ambientes urbanos } \\
\text { construidos. }\end{array}$ & $\begin{array}{l}\text { Atracción por la novedad y cualidades estéticas. } \\
\text { Bienestar subjetivo de las personas - adquieren la } \\
\text { noción de una mejor calidad de vida. } \\
\begin{array}{c}\text { Escenarios urbanos con calidad paisajistica tienden } \\
\text { a incrementar la preferencia ambiental y la } \\
\text { preservación del entorno. }\end{array}\end{array}$ & $\begin{array}{l}\text { Hipersensibilidad a la luz y/o al sonido. } \\
\text { Agotamiento físico. } \\
\text { Agobio, irritabilidad, ansiedad, agresión. } \\
\text { Desgaste a largo plazo, falta de concentración, } \\
\text { insomnio, depresión. }\end{array}$ \\
\hline
\end{tabular}

Título: Efectos en los individuos dependiendo del Recurso Ambiental Elaboración propia

Se puede destacar que el contacto con la naturaleza se relaciona con mayores efectos positivos los cuales mejoran la experiencia cotidiana generando estados de ánimo saludables, así como la reducción de tensiones y conductas hostiles, pero a pesar de que los individuos puedan adquirir cierta recuperación ante el estrés, de 
seguir desenvolviéndose en entornos insalubres su calidad de vida sigue estando comprometida. Los entornos naturales fomentan la creatividad, las capacidades afectivas y del pensamiento, así también ayudan a mejorar la longevidad y la calidad de vida de sus habitantes. Las ciudades son espacios dinámicos en donde cotidianamente se suscitan condiciones que impactan de manera tanto positiva como negativa en la salud de sus habitantes y en sus zonas circundantes, los ciudadanos se exponen a ambientes insalubres pues en el afán del crecimiento económico, la transición política y modernizadora ha dejado de lado la satisfacción y cobertura de necesidades básicas de un gran sector de la población así como la protección del entorno en relación con esas necesidades, en específico de la protección, preservación y valorización de la naturaleza sobre la cual reposa la urbe lo cual limita el disfrute de la ciudad. Tomando en cuenta que existe una relación del medio ambiente ya sea natural o construido con la movilidad urbana como parte importante para alcanzar una mayor calidad de vida, estos deben vincularse a través de espacios públicos y entornos urbanos satisfactorios que no afecten la salud pública pues desde una de las premisas del determinismo ambiental, se parte del supuesto de que el ambiente físico tiene efecto directo sobre el desarrollo humano, la conducta social y la salud.

\subsection{El ejemplo de estaciones de Metro en otros países, más allá que sólo lugares de paso}

Viajar en Metro puede ser una actividad rutinaria en la que no hay mucho que apreciar visualmente gracias a su homogeneidad en el diseño de las estaciones y la rutina en el transitar cotidiano, las redes de transporte Metro en el mundo comparten similitudes en cuanto a patrones espaciales y el diseño de trenes sin dejar de estar permeadas por referentes artísticos y culturales propios de la región; por lo que existen estaciones que son dignas de admiración pues su arquitectura original merece calificarles como obras de arte al ser lugares distintivos por los elementos históricos que le rodean; y/o por efectos de remodelación o modernización se les convierte en un espacio atractivo, de impacto visual y ambiental para sus usuarios, ejemplos de los cuales son inoperables en la Ciudad de México pues predomina el aprovechamiento de estaciones (principalmente los CETRAM) como fuentes de explotación comercial lejos de una planeación integral del espacio público.

Existen diseños arquitectónicos, urbanos y paisajísticos muy elaborados, donde se crean espacios plurifuncionales, proyectos que se encuentran en una lógica de regeneración o recuperación urbana que va más allá del mero transporte de personas y/o de explotar la actividad comercial. Respondiendo a la noción de espacios modernos en algunos países principalmente europeos y asiáticos, el medio de transporte subterráneo es considerado e integrado en la realización de proyectos urbanísticos mediante la remodelación o construcción de obras arquitectónicas de alta calidad y gran impacto tanto estético como social. Los ambientes interiores y exteriores logrados en algunas estaciones del Metro como T-Centralen en Estocolmo, Drassanes en Barcelona, Kiyevskaya en Moscú, Arts et Métiers en París, Formosa Boulevard en Taiwan, Museo TTC en Canadá, Estación de Central Park en Kaohsiung en Taiwan, Estación Parque Daan MRT de Taipei la cual es literalmente una estación dentro de un parque forestal, e incluso la estación de trenes Atocha en Madrid, por mencionar algunas; se convierten en impresionantes muestras arquitectónicas. Estaciones como las antes mencionadas reflejan la disposición administrativa y gubernamental así como la calidad de vida de sus habitantes al convertirlas en lugares atractivos y de dispersión para los usuarios locales y/o turistas invitándoles a una experiencia visual y percepción ambiental confortable al transitar por las mismas.

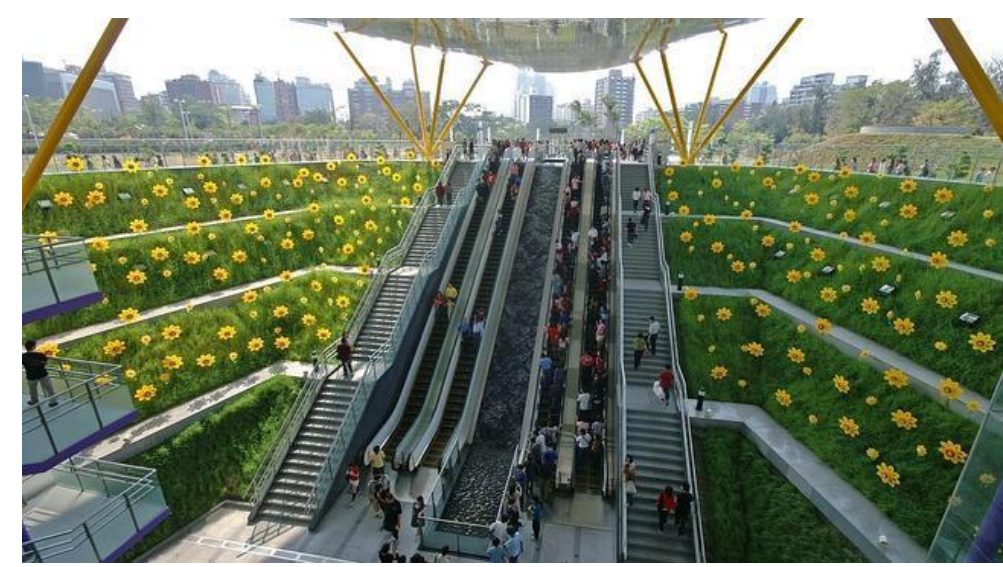

Central Park en Kaohsiung, Taiwan

Imagen propiedad de: Wikimedia Commons, Febrero 16 de 2017. 


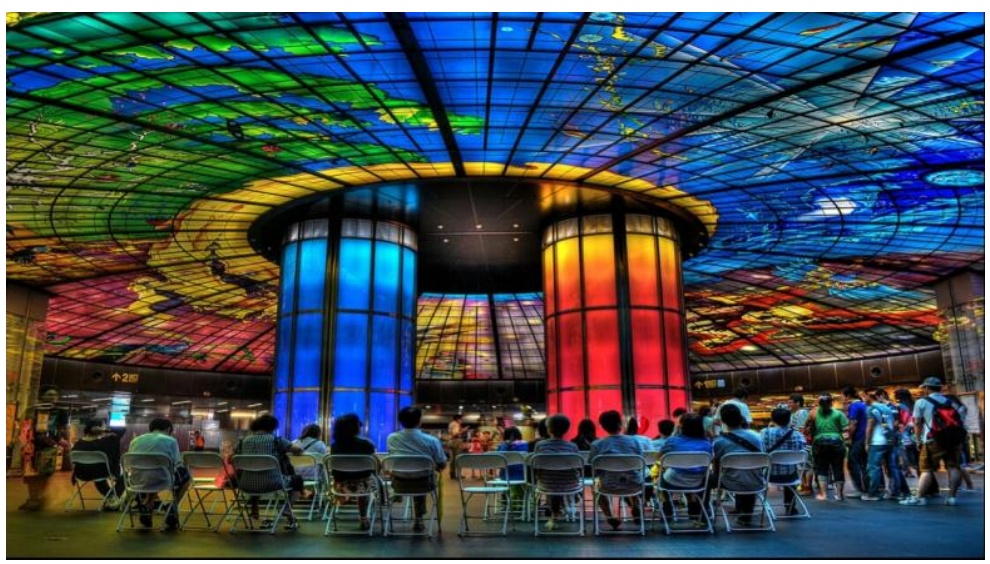

Estación Formosa Boulevard en Taiwan

Imagen propiedad de: difundir.org. Noviembre 08 de 2014.

Existen algunos ejemplos arquitectónicos de especial interés ya que cuentan con elementos de la naturaleza y una sensibilidad por la conexión psicosocial que el individuo puede establecer hacia esos espacios, quizás el ejemplo de mayor relevancia para esta investigación sea la estación de trenes Atocha en Madrid, aunque cabe destacar que no es propiamente nuestro caso de estudio sino una referencia espacial ante la carencia de estudios e investigaciones como la presente. Dicha estación de trenes se configura como un ambiente artificial que brinda experiencias y sensaciones de confort siendo amigable con los usuarios al romper con la monotonía de ciudad además de ser un espacio de actividad comercial diverso ante la afluencia de personas. Un lugar que aporta relevancia para la presente investigación al ser un ejemplo que permite concluir que es un espacio significativo ambiental y culturalmente viable el cual invita a generar vínculos entre el espacio y los usuarios de transporte.

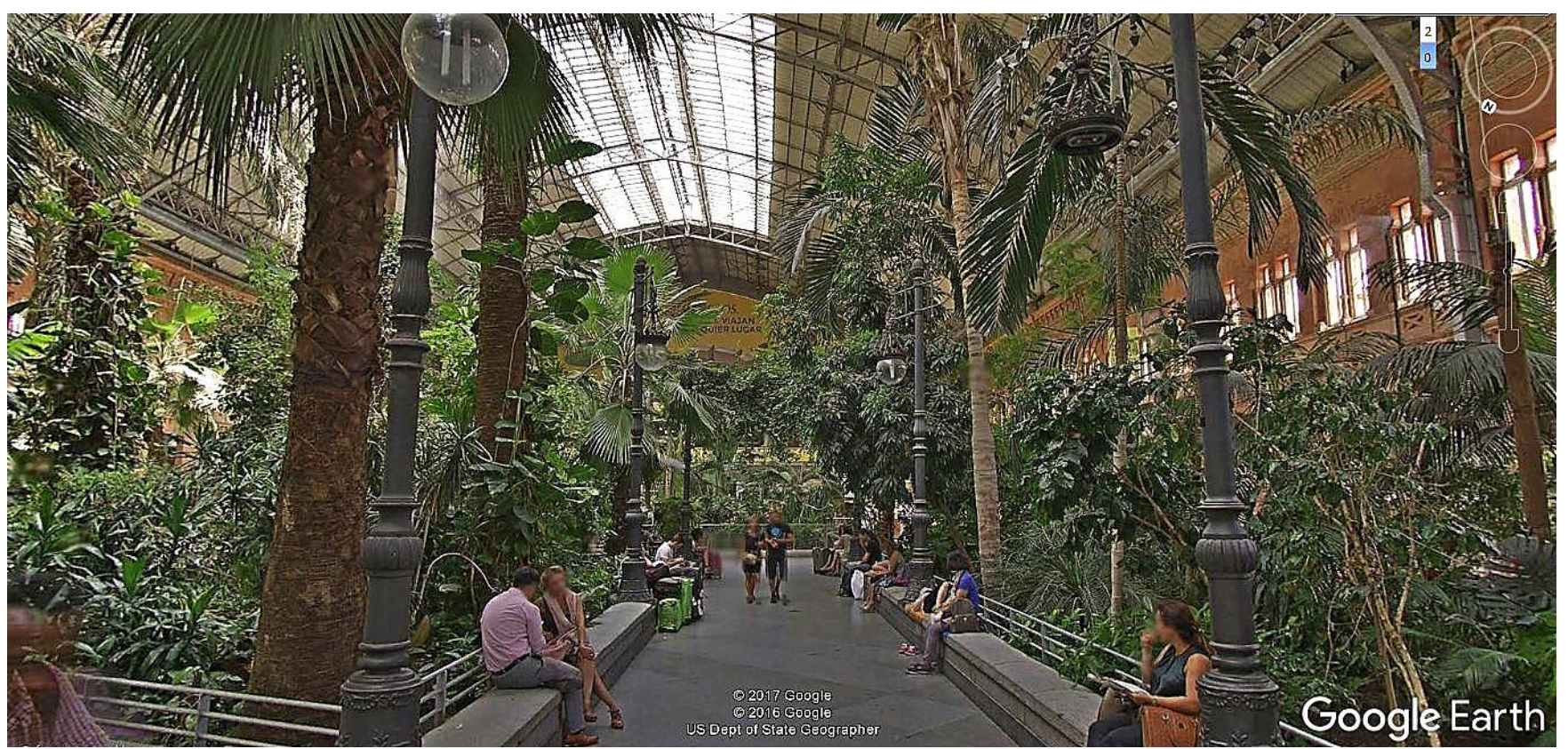

Estación de Trenes Atocha, Madrid.

Imagen captada a través de Google Earth. Febrero 02 de 2017.

El segundo ejemplo relacionado con la preferencia ambiental como parte integral de un diseño arquitectónico es el caso del Sanatorio Antituberculoso Pulmonar Paimio el cual fue construido entre 1929 y 1933, diseñado por Alvar Aalto en Paimio, cerca de Turku Finlandia (Antón, 1999). Se diseñó sobre la base del análisis de las condiciones físicas de los enfermos de tuberculosis y la búsqueda de armonía ambiental para promover el bienestar de los pacientes bajo la noción de una arquitectura funcionalista; es decir, que el diseño tuviese relación con la función que el edificio debía cumplir, estimular la terapia de recuperación disminuyendo las 
tensiones que pudiese padecer el individuo en un entorno cotidiano. El sanatorio de Paimio brindaba una experiencia hospitalaria distinta a la percibida en cualquier otro hospital de su época. Sin embargo, no se pudo constatar la eficacia del diseño de dicho sanatorio ya que el tiempo de operación y ocupación fue relativamente breve, hasta el momento no se ha podido encontrar investigaciones o casos documentados sobre el éxito de dicho proyecto en la recuperación de pacientes, por lo que queda enunciada su apuesta por un planteamiento empírico entre arquitectura terapéutica y el tratamiento ambiental.

\subsection{Consideraciones generales para la intervención espacial y la mitigación del estrés}

La finalidad de uso del STC Metro y los entornos asociados a la mayoría de las estaciones (ubicadas en zonas populares) son expresiones tangibles de la desigualdad social, la naturaleza de sus espacios por como fueron diseñados y luego mantenidos a lo largo de su vida, al deteriorarse, evidencian la flaqueza de su mantenimiento, modernización, remodelación y/o adaptación a las necesidades de acceso y desplazamiento de la población usuaria lo cual provoca un alto grado de estrés el cual puede ser un padecimiento discapacitante. La infraestructura del STC Metro se ha construido bajo usos de suelo excluyente; es decir, se ubica en zona populares donde la mayoría de la población no tiene acceso a parques y espacios públicos con naturaleza urbana a diferencia de aquellos sectores de la población que cuentan con recursos económicos suficientes para vivir y/o acudir a parques o entornos urbanos con naturaleza y áreas exclusivas, quienes tienen garantizado ese aspecto del disfrute a la ciudad y calidad de vida en su entorno. Caso contrario a la población de escasos recursos quien vive, labora y se desplaza en entornos degradados.

La psicología puede colaborar con disciplinas como la arquitectura, el urbanismo, paisajismo, y dem ás disciplinas afines en el desarrollo de entornos que mejoren no sólo los espacios públicos de las zonas circundantes a las estaciones de transbordo; sino que cumplan con el compromiso social de brindar mejoras ambientales tanto al exterior como interior que beneficien en la salud física y mental de los habitantes. La propuesta representa un recurso ambiental importante para el afrontamiento del estrés en las personas que experimentan continuamente demandas ambientales propias de escenarios caóticos en el STC Metro. Estos espacios se convertirían también en ambientes de cobijo para los operadores de los trenes en aquellos casos donde estos presencian actos de suicido por parte de los usuarios, pues los operadores de los trenes carecen de espacios donde se les brinde contención emocional en lo que respecta a primeros auxilios psicológicos. En lo que va del siglo XXI, las estaciones del Metro en la Ciudad de México han abierto sus puertas a la explotación comercial a la par que han cobijado una diversidad de estrategias y programas "con sentido social" efímeros, así también es un enclave potencial para experimentos de carácter ambiental y ecológico duraderos.

La propuesta representa un recurso ambiental importante para el afrontamiento del estrés en las personas que experimentan continuamente demandas ambientales propias de escenarios caóticos en el STC Metro. Estos espacios se convertirían también en ambientes de cobijo para los operadores de los trenes en aquellos casos donde estos presencian actos de suicido por parte de los usuarios, pues los operadores de los trenes carecen de espacios donde se les brinde contención emocional en lo que respecta a primeros auxilios psicológicos. A continuación, a groso modo se proponen algunas consideraciones y características mínimas para cumplir como ambientes restauradores en estaciones del Metro:

La intervención espacial debe contemplar aspectos tales como proyección de escenarios futuros que faciliten la movilidad peatonal, el desplazamiento libre de usuarios con acceso directo a espacios abiertos y/o andenes para evitar el hacinamiento, la incorporación de elementos naturales en estaciones donde existen espacios residuales y corredores con pasos de luz natural, disposición de mobiliario ergonómico, adecuada señalización y mejoras en la accesibilidad y diseño universal brindando mayor seguridad peatonal, áreas verdes cuya capacidad restauradora provea de relajación, áreas de desarrollo próximo potenciales para la interacción social y el esparcimiento. Dicha intervención espacial debe considerar la importancia de la participación social y comunitaria tomando en cuenta las opiniones y perspectivas de la población usuaria pues es esta quien posee el conocimiento de las necesidades espaciales y de infraestructura; donde las estaciones a intervenir se convertirían en espacios públicos y escenarios interactivos de educación ambiental al fomentar el desarrollo de nociones de preservación y revalorización del medio ambiente. A pesar del panorama actual, la salud mental parece cobrar importancia pues el 19 de julio de 2016 se instaló el Consejo de Salud Mental de la Ciudad de México el cual estará enfocado a establecer programas y acciones de prevención, detección y atención a 
personas con diversos padecimientos y trastornos mentales a fin de fortalecer el programa de salud mental del gobierno de la ciudad; dicho consejo incluirá la participación del STC Metro para acciones aún no definidas. ${ }^{6}$

\section{CONCLUSIONES}

El nivel de ingreso es determinante en la elección de los modos de desplazamiento pues las personas de bajos ingresos tienen como única opción el transporte público, a diferencia de las personas con mayor percepción económica pues estas cuentan con diversas opciones de transporte automotor y de mayor confort; por lo que la población de escasos recursos sufre mucho más las consecuencias por el uso del transporte público Metro como se ha mencionado anteriormente. Sin importar cualesquiera que sean las condiciones objetivas de desplazamiento de los individuos la movilidad urbana es una necesidad básica que debe ser satisfecha, donde el esfuerzo que requieren los desplazamientos no repercuta negativamente en la salud tanto física como mental. La Recomendación 14/2016 de la Comisión de Derechos Humanos del Distrito Federal (2016) menciona que una vía para reducir la contaminación ambiental en la Ciudad de México y el congestionamiento vial, es mejorar la infraestructura del STC Metro a través de condiciones ambientales que restauren el deterioro y resuelvan el mantenimiento pero que a su vez, garanticen el derecho de los ciudadanos a un nivel de vida en cuestión de transporte y movilidad adecuados. La clase trabajadora principal usuaria del Metro es un sector de la población claramente desatendido por las políticas de atención a la salud, seguridad social y empleo, además de ser excluido de la planeación en lo que a movilidad, transporte y desarrollo urbano de la Ciudad de México se refiere; pues la infraestructura privilegia la consolidación de la iniciativa privada evidenciando que la calidad del entorno que se construya alrededor de ésta servirá para fines de explotación comercial, dejando de lado la creación de espacios públicos y entornos urbanos que promuevan bienestar y mejoras en la calidad de vida.

EI STC Metro limita la diversidad de uso, las interacciones sociales y culturales ajenas al desplazamiento que en sus estaciones puedan darse, posee una infraestructura cuyos espacios son sometidos a una regulación por parte de la administración pública la cual restringe cualquier posibilidad ajena al aprovechamiento de su explotación comercial; en este sentido limita la incorporación de mejoras ambientales. Por ejemplo, véase lo relacionado a las posibilidades de expansión y multiplicación en la red del concepto llamado Túnel de la Ciencia en la estación la Raza, inaugurado en 1988 y considerado como el primer museo científico-cognoscitivo del mundo pero cuya opción ha quedado desatendida; lo cual abriría camino a la intervención espacial con la integración de ambientes restauradores mejorando la calidad de sus espacios. Es por ello que se debe externar y visibilizar la participación de especialistas de diversas disciplinas bajo las cuales se puede plantear, diseñar y proponer espacios más humanos en este transporte.

La clase obrera y trabajadora es la materia prima que mantiene y sostiene la economía en la ZMCM sin embargo, se deja de lado la importancia y trascendencia del bienestar y equilibrio mental de este sector de la población corroborándose con la ausencia de políticas de salud mental, con las limitaciones de una vinculación entre áreas de aplicación y las aportaciones multidisciplinarias; así como con el inexistente presupuesto para la atención de la salud mental. Lo que se analiza con esto, no es apostar por vías que atiendan la salud mental al igual que la salud física para que ambas mantengan a los individuos con una mayor fortaleza y por consiguiente sucumban aun más ante dicho sistema de explotación económica. La falta de atención sobre aspectos que incumben a la salud mental repercuten inevitablemente en lo social, pues una sociedad más sana mentalmente tendrá mayores posibilidades de desarrollo; incluso podría pensarse que la falta de importancia y atención a la salud mental como parte integral del bienestar humano se dejan de lado intencionalmente, porque en la medida en que una población obtenga mayores recursos emocionales y cognitivos se estarían abriendo las puertas para un mayor nivel de empoderamiento en la resolución de conflictos económicos, políticos y culturales.

Si bien los servicios de atención a la salud se ven mermados ante la ineficiencia de las instancias pertinentes, la salud mental al no estar contemplada en la lógica de las políticas para el desarrollo humano, bienestar y las vías para mejorar la calidad de vida de los habitantes, la salud mental se ve más que comprometida; sin embargo, las intervenciones urbanísticas desde un abordaje multidisciplinario puede significar no una medida paliativa para disminuir las afectaciones a la salud mental, sino a generar una ciudad más humana que diseñe escenarios a

\footnotetext{
${ }^{6}$ Cruz, A. (20 de Julio de 2016). El Gobierno de la Ciudad de México instala el Consejo de Salud Mental. La Jornada. Recuperado de http://www.jornada.unam.mx
} 
futuro mucho más habitables y prósperos en apego al cumplimiento de los derechos humanos. Ante la falta de recursos económicos y los constantes recortes presupuestales al sector salud, el aumento de padecimientos como el estrés, se acentúan y potencializan como un problema de salud pública ya que la población de escasos recursos es un sector ya de por si vulnerable, se incorpora a un mercado laboral precario además de desenvolverse en entornos urbanos caóticos e insalubres en donde no sólo generan estados de tensión constante, sino que pueden detonar otros padecimientos más severos a causa del estrés, ya que este puede estar aunado a otras enfermedades fisiológicas y/o mentales preexistentes en los individuos. Si es posible evaluar los impactos negativos en la salud mental de los usuarios del transporte Metro, así también se podrían identificar los impactos positivos de las intervenciones espaciales con ambientes restauradores.

Existe una carencia de investigaciones hechas en México que documenten los impactos sociales en materia de salud mental desde la diversidad de actividades humanas condicionadas por el desarrollo económico y la vida en las ciudades, cuyo trinomio movilidad - medio ambiente - calidad de vida, carece de entornos y espacios públicos cuyos proyectos de intervención espacial, remodelación y/o regeneración urbana desestiman la importancia de las cualidades restauradoras del ambiente natural y sus beneficios para la salud de la población, principalmente la de más escasos recursos. En el caso del STC Metro un espacio ampliamente reglamentado, de existir la posibilidad de incursionar en la conversión espacial se corre el riesgo de derivar en contradicciones en la búsqueda de soluciones y/o acciones propositivas para el beneficio social, por ejemplo, a través de la intervención espacial con ambientes restauradores y la proliferación de estos en la Red del Metro, puede dar cabida al aprovechamiento de estos escenarios para la inversión privada y explotación comercial como marca la tendencia actual, la inserción de centros comerciales en los CETRAM. Más allá de favorecer zonas de desarrollo económico, se busca generar estrategias en la prevención de la salud pública principalmente de aquellos sectores más desprotegidos.

Existe un imperante reduccionismo de la importancia medio ambiental pues en la ciudad de México hay una gran ausencia de espacios públicos con significativa importancia ambiental, es por ello que el presente trabajo apuesta por la consideración del diseño e intervención espacial en las estaciones del STC Metro ambientadas con elementos de la naturaleza, con la finalidad de abrir posibilidades de estudio, gestión y desarrollo de la articulación exitosa entre ambientes naturales con espacios urbano-arquitectónicos que sean contemplados en futuras políticas de movilidad y transporte, tendientes a mejorar la interacción de la población con su entorno urbano principalmente por las cualidades restauradoras pues con ello se podrá reducir el estrés o al menos proveer un beneficio directo de las personas que viven en condiciones de pobreza extrema desalentando su creciente vulnerabilidad en materia de salud mental.

\section{BIBLIOGRAFÍA}

AUGÉ, MARC. (2008). Los No Lugares, Espacios del Anonimato. Barcelona: Gedisa.

ALVAR AALTO. (2000). "La Humanización de la Arquitectura". En GÖRAN SCHILDT. Alvar Aalto de palabra y por escrito. Madrid: El Croquis.

ANTÓN CAPITEL. (1999). Proyecto y Método. Madrid: Ediciones Akal, S. A.

ASCHER, FRANCOISE.(2004). Los Nuevos Principios del Urbanismo. Madrid: Alianza.

CAMACHO DÁVALOS, SOL. (2014) Megacentralidades: Propuesta de integración de los CETRAM al Desarrollo Urbano de la Ciudad de México. México: ITDP.

CASTELLS, MANUEL. (2004). La cuestión urbana. España: Siglo XXI.

CHARLES J. HOLAHAN. (2008). Psicología Ambiental, un enfoque general. Austin Texas: Limusa.

DE LA FUENTE, RAMÓN. (1978). El ambiente y la salud mental. Simposio "Ambiente y Salud". Academia Nacional de Medicina, México, Julio. 
FERNÁNDEZ RAMÍREZ, B. (2008). Psicología de la Ciudad: Debate sobre el espacio urbano. Barcelona: UOC.

GONZÁLEZ MANTEROLA, C. (1997). Treinta años de hacer el Metro: Ciudad de México. México: Espejo de Obsidiana.

GÖRAN DAHLGREN M. (2010). Estrategias europeas para la lucha contra las desigualdades sociales en salud: Desarrollando el máximo potencial de salud para toda la población. España: Ministerio de Sanidad y Política Social.

HERNÁNDEZ, B. y PELCASTRE, B. (2007). Psicología social de la salud, en Tratado de psicología social. México: Anthropos - UAM.

ISLAS, V. y LELIS, M. (2007). Análisis de los Sistemas de Transporte. Vol 1: Conceptos Básicos. México: IMT. No. 307.

JASSO, L. et al. (1998). Seguridad e Higiene Industrial. México: UAM Iztapalapa.

KWIATKOWSKA, T. y E ISSA, J. (1998). Los caminos de la ética ambiental. Una antología de textos contemporáneos. México: Plaza y Valdés. S.A. De C.V.

LEZAMA, J. (1993). Las aportaciones de Lefebvre en Teoría Social, Espacio y Ciudad. México: Colmex.

MEDINA, S. (2013). Reciclaje y reaprovechamiento de nodos de transporte: el caso de los centros de transferencia modal ligados al Metro. México: UNAM.

MORENO, O. (1986). El origen de las Ciudades: La Ciudad Occidental. En La ciudad mexicana hoy y mañana (Retos y perspectivas). México: UNAM.

NAVARRO, B. (1988). El traslado masivo de la fuerza de trabajo en la ciudad de México. México: Plaza y Janés, S.A. de C.V.

NAVARRO, B. y GONZÁLEZ, O. (1989). Metro, Metrópoli, México. México: UAM - UNAM.

OBANDO, O. (2010). Psicología Social Crítica, Aportes y aplicaciones sobre el lenguaje, ciudadanía, convivencia, espacio público, género y subjetividad. Colombia: Programa Editorial Universidad del Valle.

RAMÍREZ VELÁZQUEZ, B. y PRADILLA COBOS, E., (2013). ¿Ecología urbana? Interpretación del pensamiento ambiental latinoamericano. En CASTRO RAMÍREZ M., Teorías sobre la ciudad en América Latina (743-774). México: UAM-EDIMPRO.

RODRÍGUEZ, J. NAVARRO, B. (1999). El transporte urbano de pasajeros de la ciudad de México en el siglo XX. Cuaderno "así funciona tu ciudad". México: Comité Editorial Gobierno del Distrito Federal.

SACASA, M. (2012). El Indice de Desarrollo Humano en México: cambios metodológicos e información para las entidades federativas. México: Programa de las Naciones Unidas para el Desarrollo.

SÁNCHEZ, M., GUTIÉRREZ, C. (2010). Estrés y salud. Aportaciones desde la psicología social. México: UAM I Miguel Ángel Porrúa.

SJOBERG, G. (1998). Antología de Sociología Urbana. México: UNAM.

\section{Revistas}

BUILES CORREA, M. y BEDOYA HERNÁNDEZ, M. (2006). La psicoeducación como experiencia narrativa: comprensiones posmodernas en el abordaje de la enfermedad mental. Revista Colombiana de Psiquiatría (Colombia), 4, 463-475. 
COOPER MARCUS, C. (2007). Healing Gardens in Hospitals, IDRP Interdisciplinary Design and Research e-Journal (EUA). Volume I, Issue I: Design and Health, 1-27.

DÍAZ VELÁZQUEZ, E. (2010). Ciudadanía, identidad y exclusión social de las personas con discapacidad. Política y Sociedad (Madrid), 1. 115-135.

DORANTES RODRÍGUEZ, C. y MATUS GARCÍA, G. (2002). El estrés y la ciudad. Revista del Centro de Investigación (México), 18. 71-77.

GRO HARLEM, B. (2002). Salud y desarrollo sostenible. ICE Revista de economía (España), 800. 173-179.

JIRÓN, P , LANGE, C. Y BERTRAND, M. (2010). Exclusión y desigualdad espacial: Retrato desde la movilidad cotidiana. Revista INVI (Chile), 68, 15-57.

JUÁREZ, F. (2011). El concepto de salud: Una explicación sobre su unicidad, multiplicidad y los modelos de salud. International Journal of Psychological Research. (Colombia), 4.

MARTÍNEZ, J., MONTERO, L., y CÓRDOVA, A. (2014). Restauración psicológica y naturaleza urbana: algunas implicaciones para la salud mental. Salud Mental.. (México), 3, 217-224.

OSORIO, H. (2007). La salud sustentable y ambiente social. Aportes revista de la facultad de economía BUAP. (México), 36, 79-92.

PAOLA, M., CARLOS, V. Y MARÍA, S. (2010). Exclusión y Desigualdad Espacial: Retrato desde la movilidad cotidiana. Revista INVI (Chile), № 68, 15-57.

SALAZAR, O. (2013). De Liebres, tortugas y otros engendros: movilidades urbanas y experiencia del espacio público en la Bogotá contemporánea. Revista Colombiana de antropología (Colombia), 49, 15-40.

SÁNCHEZ, M., DE LA GARZA, A. (2015). Estudio del impacto de imágenes ambientales en los aspectos emocionales. Revista de Psicología (Perú) 2, 387-410.

TOMÁS, R. y AMÉRIGO, M. (2011). Comportamiento socioespacial en los transportes públicos urbanos: una aproximación cualitativa. Nueva Época (España) 1, 6-29.

\section{Ordenanzas o Decreto:}

Comisión de Derechos Humanos del Distrito Federal. (2013). Propuesta General 01, Manifestación, movilidad y derechos humanos: una propuesta de aproximación desde los estándares internacionales. México. Diciembre de 2013.

Comisión de Derechos Humanos del Distrito Federal. (2016). Recomendación 14/2016.

Diario Oficial de la Federación. (2014). Reglamento Federal de Seguridad y Salud en el Trabajo. México. Noviembre de 2014.

Diario Oficial de la Federación. Ley Federal del Trabajo. (2015). México, Junio de 2015.

\section{Publicaciones Institucionales}

Consejo de Evaluación del Desarrollo Social del Distrito Federal. (2011). Evaluación del diseño e instrumentación de la política del transporte público colectivo de pasajeros en el Distrito Federal. México. Febrero de 2011.

Dirección de Análisis y Programación Sectorial de la Vicepresidencia de Infraestructura de CAF. (2011). Desarrollo Urbano y Movilidad en América Latina. Panamá. 
Fideicomiso Maestro del Metro. (2014). Once compromisos asumidos por el Sistema de Transporte Colectivo. México. Agosto de 2014.

Gaceta Oficial del Distrito Federal. (2013). Áreas de oportunidad: Transporte público. México. Septiembre de 2013.

Gaceta Oficial del Distrito Federal. (2014). Programa Integral de Movilidad 2013-2018. México. Octubre de 2014. Organización Mundial de la Salud. (2001). Informe sobre la Salud en el Mundo 2001. Salud Mental: nuevos conocimientos, nuevas ventajas. Ginebra, Suiza.

SANDOVAL, J. (2006). La Salud Mental en México. División de Política Social. Servicio de Investigación y Análisis. Cámara de Diputados. México.

Senado de la República y ONU-HABITAT. (2015 ). Reporte Nacional de Movilidad Urbana en México 2014 - 2015. México. Abril de 2015.

Gabinete de Comunicación Estratégica. (2016). Las ciudades más habitables de México 2016. México. Octubre de 2016.

\section{Fuentes Electrónicas:}

http://www.metro.df.gob.mx (Consulta: 23/08/2016)

http://www.metrobus.cdmx.gob.mx (Consulta: 11/09/2016)

http://www.mexico.itdp.org (Consulta: 30/06/2015)

http://www.thecityfixmexico.org (Consulta: 21/05/2016)

http://www.metrodemedellin.gov.co (Consulta: 20/04/2015)

http://www.salud.df.gob.mx (Consulta: 29/05/2015)

http://www.amf.org.mx (Consulta: 30/10/2016)

http://www.imt.mx (Consulta: 09/06/2015)

http://www.infodf.org.mx (Consulta: 21/05/2016)

http://www.cetram.cdmx.gob.mx (Consulta: 18/09/2016)

http://www.jornada.unam.mx (Consulta: 20/07/2016)

http://www.xdata.gabinete.mx (Consulta: 18/11/2016) 